Rochester Institute of Technology

RIT Scholar Works

Articles

Faculty \& Staff Scholarship

2004

\title{
A Dynamic and Stochastic Analysis of Fertilizer Use in Swidden Agriculture
}

Gregory DeAngelo

Rochester Institute of Technology

Amitrajeet A. Batabyal

Rochester Institute of Technology

Follow this and additional works at: https://scholarworks.rit.edu/article

\section{Recommended Citation}

Amitrajeet Batabyal and Gregory DeAngelo, (2004) "A dynamic and stochastic analysis of fertilizer use in swidden agriculture", Economics Bulletin, Vol. 17 no.3 pp. 1-10

This Article is brought to you for free and open access by the Faculty \& Staff Scholarship at RIT Scholar Works. It has been accepted for inclusion in Articles by an authorized administrator of RIT Scholar Works. For more information, please contact ritscholarworks@rit.edu. 


\section{A Dynamic and Stochastic Analysis of Fertilizer Use in}

\section{Swidden Agriculture ${ }^{1}$}

by

\section{Gregory DeAngelo}

and

\section{Amitrajeet A. Batabyal $^{3}$}

1

This paper is based on an independent study project undertaken at RIT by the first author under the supervision of the second author. Batabyal thanks the Gosnell endowment at RIT for financial support. The usual disclaimer applies.

2

Department of Economics, Rochester Institute of Technology, 92 Lomb Memorial Drive, Rochester, NY 14623-5604, USA. Internet hypcar51@ hotmail.com

3

Department of Economics, Rochester Institute of Technology, 92 Lomb Memorial Drive, Rochester, NY 14623-5604, USA. Internet aabgsh@rit.edu 


\title{
A Dynamic and Stochastic Analysis of Fertilizer Use in
}

\section{Swidden Agriculture}

\begin{abstract}
The number of times a crop can be harvested on a cleared parcel of forest land (CPFL) before this land must be fallowed is dependent on the decision to use or not to use fertilizers to enhance soil fertility. As such, we first construct a theoretical model of fertilizer use by a swidden cultivator when this cultivator can choose whether or not to enhance soil fertility by using fertilizers. Second, we analyze two different policies (fertilizer use and no fertilizer use) for overseeing the problem of soil fertility deterioration on the CPFL. Finally, we identify a particular likelihood function and we show that whether the problem of soil fertility impairment is best addressed with a fertilizer use policy or with a no fertilizer use policy depends essentially on this likelihood function.
\end{abstract}

Keywords: Fallow, Fertilizer, Land Use, Swidden Agriculture, Uncertainty

JEL Codes: D81, Q15, Q24 


\section{A Dynamic and Stochastic Analysis of Fertilizer Use in}

\section{Swidden Agriculture}

\section{Introduction}

Small-scale farmers in most tropical developing countries practice swidden or slash-and-burn agriculture. There are five key stages in the swidden cycle. ${ }^{4}$ First, large forest trees are cut down by the farmer, the debris is cleared, and the cut growth is burned. The burning of the forest vegetation clears the ground for planting and releases vital nutrients. As the burned vegetation decomposes, the organic levels in the soil rise and this enhances the soil's fertility. Second, before rains cause soil erosion and before the ash bed can be blown or leached away, planting begins. This generally involves the dropping of seeds into shallow holes made by dibble sticks. Third, with the onset of the rainy season, systematic precipitation leads to speedy plant growth. This speedy growth is sometimes accompanied by the concurrent growth of weeds. These weeds are regularly removed by the swidden cultivator to preclude them from taking nutrients away from the crop under cultivation. Fourth, during the harvesting season, the cultivator protects the crop from pests and (s)he often uses simple implements to harvest the grain. In the process of harvesting the grain, the cultivator retains some of the best seeds for the next planting. Finally, and this is the crucial stage, the cleared parcel of forest land (hereafter CPFL) is left fallow after one or two harvests. Within a couple of years, a closed canopy of secondary forest develops. If the CPFL is left fallow for an adequately long period of time then nutrients will return to the soil and this will permit the above described swidden cycle to be

4

For more on this and related issues, see Dove (1983), Peters and Neuenschwander (1988), Pearce and Warford (1993), Brown and Pearce (1994), Swinkels et al. (1997), and Coomes et al. (2000). 
repeated.

Despite the significance of swidden agriculture in tropical developing countries, there is some controversy about the merits of this kind of agriculture. On the one hand, scholars such as Dove (1983), Southgate (1990), and Pearce and Warford (1993) have criticized this kind of agriculture. Specifically, these scholars have claimed that swidden agriculture is environmentally harmful because the land clearing activities of swidden cultivators is directly associated with extensive and ruinous tropical forest deforestation. On the other hand, a second group of scholars including Peters and Neuenschwander (1988) and Dufour (1990) have argued that in some situations, swidden agriculture based on long fallow periods can be an ecologically and an economically sustainable enterprise in tropical forests.

Batabyal and Lee (2003) and Batabyal and Beladi (2004) have recently argued convincingly that the viability of swidden agriculture in the long run depends on a CPFL being fallowed at appropriate points in time and for appropriate lengths of time. ${ }^{5}$ Although this is certainly true, as noted by Dickinson (1972), Farnsworth and Golley (1973), and Eckholm (1976), what is also true is that swidden cultivators can-and often have attempted to-increase the number of harvests on a particular CPFL before this CPFL must be fallowed by applying natural and/or chemical fertilizers. However, beyond recognizing this essential point, scholars have not theoretically analyzed the fertilizer use decision problem faced by swidden cultivators. In addition, keeping in mind the dynamic and the stochastic setting in which swidden cultivators typically operate, scholars have not studied the conditions under which it is optimal to use fertilizers.

5

For a more expansive discussion of this and related points, see Hofstad (1997), Silva-Forsberg and Fearnside (1997), Coomes et al. (2000), Li et al. (2000), and Udaeyo et al. (2001). 
Given this state of affairs, our paper has three goals. Section 2 describes a dynamic and stochastic model of fertilizer use. Section 3 first analyzes two different policies (fertilizer use and no fertilizer use) for overseeing the problem of soil fertility deterioration. Next, this section identifies a specific likelihood function and it shows that in addition to cost considerations, whether the problem of soil fertility deterioration is best addressed with a fertilizer use policy or a no fertilizer use policy depends primarily on this likelihood function. Finally, section 4 concludes and discusses ways in which the research of this paper might be extended.

\section{The Theoretical Framework}

This paper's model is adapted from previous research by Antelman and Savage (1965), Batabyal and Yoo (1994), and Ross (1996, chapter 8). Consider a swidden cultivator and a dynamic and stochastic parcel of forest land that has just been cleared for the planting of a particular crop. As explained in section 1, this cultivator follows the swidden cycle and thereby obtains grain output from successive harvests of the crop under study. Now, ceteris paribus, our cultivator would like to repeat as many swidden cycles as possible on the CPFL but in doing this, (s)he must contend with the deterioration in soil fertility on this CPFL. Put differently, our cultivator realizes that after a certain number of crop harvests, the CPFL will not yield any tangible grain output and hence this CPFL will need to be fallowed.

It is generally possible to extend the useful life of a CPFL, i.e., to increase the number of harvests before the land is fallowed, by using fertilizers. ${ }^{6}$ This is a rationale for a policy of fertilizer use by our cultivator. However, as noted by Dickinson(1972), Eckholm(1976), and others, fertilizers 
are costly-chemical fertilizers more so than natural ones-and because swidden cultivators are typically poor, small-scale farmers, they often will not possess the financial resources to use fertilizers. In other words, although fertilizer use can be economically profitable, the cost of fertilizer use frequently serves as a deterrent against its use.

We can now state the two policies that are available to our swidden cultivator. The first policy is a passive one in which no fertilizer is used. Clearly, when our cultivator uses this policy, (s)he is relying solely on natural or environmental factors to delay the deterioration in soil fertility. In contrast, the second policy is an active one in which the cultivator uses fertilizers and thereby actively attempts to retard the deterioration in soil fertility.

The essential stock variable that is affected by the repeated planting of the crop in question is the stock of soil fertility. Notionally, this stock is very much like the stock of an exhaustible natural resource such as oil. Just as repeated extraction of this exhaustible resource draws down its stock, similarly, repeated planting of a crop lowers the stock of soil fertility. The reader should note that because of a variety of reasons, not the least of which is the swidden cultivator's own crop planting actions, the lowering of the stock of soil fertility is typically probabilistic and not deterministic. To account for this aspect of the problem, we shall think of the soil fertility stock as a stochastic process that can exist in one of many possible states. To this end, let state 0 be the best possible state of the soil fertility stock. The reader should think of this state as corresponding to the state in which our CPFL exists immediately after the completion of the first stage in the five stage swidden cycle that we described in section 1 . To model the stochastic soil fertility degradation process, we shall say that the stock of soil fertility changes state in accordance with a Wiener process with drift $\delta>0 .^{7}$

\footnotetext{
For more on the Wiener process, see Ross (1996, chapter 8) and Ross (2003, chapter 10).
}

7 
With repeated planting of the crop in question, soil fertility on the CPFL deteriorates, our Wiener process changes state, and eventually this process gets to a "breakdown" state in which the land must be fallowed. Denote this breakdown or fallow state by $f$. The idea here is that once this fallow state is reached, our swidden cultivator's reliance on the passive policy in which natural or environmental factors alone retard the deterioration in soil fertility, has run its course. Consequently, the CPFL must now be left fallow for a certain period of time. ${ }^{8}$ When this is done, a secondary forest cover gradually emerges on the CPFL. Mathematically, this means that our Wiener process eventually returns to state 0 . In other words, the state of the stock of soil fertility corresponds, once again, to the state in which the CPFL exists right after the completion of the first stage in the five stage swidden cycle. When the fallow state is reached, our cultivator must abandon the CPFL under study and this cultivator must now look for and clear an alternate parcel of forest land. These land clearing activities are costly. As such, let us denote the cost of the passive or no fertilizer use policy by $c(f)$.

We now focus on the active policy in which our swidden cultivator uses fertilizers. The reader should note that we are using the word "fertilizer" in a general way. In particular, this active policy may involve the use of a natural or a chemical fertilizer. Further, depending on the crop that is being grown, it may even make sense to use more than one fertilizer. The key thing to note is that in contrast with the previously described passive or no fertilizer use policy, the active policy always involves fertilizer use. Finally, note that for the active policy to make sense, our swidden cultivator must use the fertilizer(s) before the Wiener process hits the fallow state $f$.

Now, because our swidden cultivator operates in a probabilistic environment, the pursuit of

8

An interesting question that emerges in this context is the determination of the optimal length of time during which the CPFL ought to be left fallow. This question has been addressed in Batabyal and Beladi (2004). 
the fertilizer use policy increases the likelihood that soil fertility on the CPFL will improve but it does not guarantee that soil fertility will improve. Specifically, if the state of the Wiener process is $b$ and the active or fertilizer use policy is used, then this policy will be successful in improving soil fertility with probability $p(b)$ and it will be unsuccessful with probability $1-p(b)$. Why might a fertilizer use policy be unsuccessful in raising soil fertility? Two possible reasons come to mind. First, our swidden cultivator may use too little or too much fertilizer and, as a result, soil fertility might not be impacted in any significant manner. Second, this cultivator may use the wrong fertilizer and hence, once again, there will be no improvement in soil fertility. If the fertilizer use policy is successful in improving soil fertility then we suppose that our Wiener process returns to state 0 . In other words, the state of the stock of soil fertility corresponds to the state in which the CPFL exists right after the completion of the first stage in the five stage swidden cycle. In contrast, if this fertilizer use policy is unsuccessful in improving soil fertility then the Wiener process is assumed to go to state $f .{ }^{9}$ The cost of attempting to improve soil fertility actively in state $b$ is $c(b)$. Our charge now is to ascertain which policy, active or passive, minimizes the long run average cost per time.

\section{Active versus Passive Policies}

\subsection{Long run average cost per time}

To calculate this cost function, we shall use renewal theory (see Ross (1996, chapter 3) and Ross (2003, chapter 7)). Further, as far as the fertilizer use policy is concerned, we shall focus attention on those policies that attempt to raise soil fertility when our Wiener process is in state $b$,

9

We understand that the failure of the fertilizer use policy does not necessarily mean that soil fertility has declined to such an extent that our Wiener process must go to state $f$. We make this assumption primarily for reasons of mathematical tractability. Having said this, we recognize that it is possible that the Wiener process will goes to some intermediate state $e$, where $e$ is worse than $b$ but better than state $f$. 
where $0<b<f$. Given this stipulation, note that every time our Wiener process returns to state 0 , we have a renewal. Consequently, we can use a prominent result in renewal theory, namely, the renewalreward theorem, ${ }^{10}$ to calculate the long run average cost that we seek. Now, if we envision a cycle being completed every time a renewal occurs, then the renewal-reward theorem tells us that the long run average reward or cost (a negative reward) is given by the expected positive or negative return earned in a cycle divided by the length of this cycle.

We now adapt the renewal-reward theorem to fit the problem that we are analyzing. This gives us

$$
\text { Long Run Average Cost }=\frac{E[\text { Cost per Cycle }]}{E[\text { Length of Cycle }]},
$$

where $E[\cdot]$ is the expectation operator. Now, calculating the numerator on the right-hand-side (RHS) of equation (1) is fairly routine. Some thought tells us that the average cost per cycle is given by $c(b)+\{1-p(b)\} c(f)$. Hence, in symbols, we have

$$
E[\text { Cost per Cycle }]=c(b)+\{1-p(b)\} c(f) .
$$

The calculation of the average length of a renewal cycle is more involved. We proceed as in Batabyal and Yoo (1994). Let us represent the average time it takes for our Wiener process to reach state $b$ with the function $k(b)$. Now, it is well known that a Wiener process has independent and stationary increments. ${ }^{11}$ Therefore, for any two states of the process $b_{1}$ and $b_{2}$, we can write

For more on the renewal-reward theorem, see Ross (1996, p. 133) or Ross (2003, p. 417).

11

For more on these notions, see Ross (1996, chapter 8) and Ross (2003, chapter 10). 


$$
k\left(b_{1}+b_{2}\right)=k\left(b_{1}\right)+k\left(b_{2}\right)
$$

Now, the previously mentioned properties of Wiener processes and equation (3) together tell us that the function $k(b)$ has the form $k(b)=z \cdot b$, where $z$ is a constant. It can be demonstrated that the constant $z=1 / \delta$ and therefore $k(b)=b / \delta .^{12}$ This last finding permits us to conclude that

$$
E[\text { Length of Cycle }]=\frac{b}{\delta}
$$

Now, using equations (2) and (4) together, we get

$$
[\text { Long Run Average Cost }]_{A}=\frac{E[\text { Cost per Cycle }]}{E[\text { Length of Cycle }]}=\frac{\delta[c(b)+\{1-p(b)\} c(f)]}{b} \text {. }
$$

Equation (5) tells us that the long run average cost of raising soil fertility with the active or fertilizer use policy is given by the ratio of the weighted sum of the two cost expressions $c(b)$ and $c(f)$ to the state $b, 0<b<f$, in which this policy is utilized.

Our charge now is to ascertain the long run average cost of the passive or no fertilizer use policy. For this policy, it is easy to see that $E[$ Cost of $C y c l e]=c(f)$. Further, following the logic of the derivation that led to equation (4), we deduce that $E[$ Length of $C y c l e]=f / \delta$. Hence, putting these two pieces of information together, we reason that

$$
\text { [Long Run Average Cost }]_{P}=\frac{E[\text { Cost per Cycle }]}{E[\text { Length of Cycle }]}=\frac{\delta c(f)}{f} \text {. }
$$

For additional details on this point, see Batabyal and Yoo (1994) and Ross (1996, chapter 8). 
According to equation (6), the long run average cost of the passive policy in which our swidden cultivator relies exclusively on natural or environmental factors to improve soil fertility is given by the ratio of the product of the drift parameter of our Wiener process $\delta$ and the cost of locating and clearing an alternate parcel of forest land $c(f)$ to the fallow state $f$.

Examining equation (5) it should be clear to the reader that for a specific likelihood function $p(b)$, we can always use calculus to minimize this long run average cost function. Even so, we now discuss an important point and that point is this: The choice between the active policy and the passive policy (see equations (5) and (6)) is, in large part, contingent on the likelihood function $p(b)$.

\subsection{Significance of the likelihood function}

To see the above point, let us first equate the RHSs of equations (5) and (6). This gives us a threshold value for the likelihood function and that value is

$$
p(b)=\frac{c(b)}{c(f)}-\frac{b}{f}+1
$$

When the likelihood function $p(b)$ equals the RHS of equation (7), our swidden cultivator will be indifferent between pursuing the fertilizer use policy and the no fertilizer use policy because both policies give rise to the same long run average cost.

In contrast, consider the case where $p(b)=1-b / f$. In this case $1-p(b)=b / f$ and substituting this value into the RHS of equation (5) and then comparing the result with the RHS of equation (6), we see that

$$
\text { [Long Run Average Cost }]_{A}=\frac{\delta c(b)}{b}+\frac{\delta c(f)}{f}>\frac{\delta c(f)}{f}=[\text { Long Run Average Cost }]_{P} \text {. }
$$


Equation (8) explicitly tells us that when the likelihood function is $p(b)=1-b / f$, the optimal course of action for our swidden cultivator is to not use fertilizers on the CPFL. This cultivator does better, i.e., bears a lower long run average cost by relying solely on natural or environmental factors to improve soil fertility on the CPFL.

As a second illustration, consider the likelihood function $p(b)=\{c(b) / c(f)\}-(b / f)+2$. In this case $1-p(b)=(b / f)-\{c(b) / c(f)\}-1$ and, once again, substituting this value into the RHS of equation (5) and then comparing the result with the RHS of equation (6), we see that

$$
[\text { Long Run Average Cost }]_{A}=\frac{\delta c(f)}{f}-\frac{\delta c(f)}{b}<\frac{\delta c(f)}{f}=[\text { Long Run Average Cost }]_{P}
$$

In this second illustration, equation (9) clearly tells us that when the likelihood function is $p(b)=\{c(b) / c(f)\}-(b / f)+2$, it is optimal for our swidden cultivator to pursue the active policy in which (s)he relies on fertilizers — and not on natural or environmental factors — to improve soil fertility on the CPFL. Put differently, this cultivator bears a lower long run average cost by using fertilizers to raise soil fertility on the CPFL.

\section{Conclusions}

In this paper, we provided a theoretical analysis of the "to use or not to use fertilizer" question facing a swidden cultivator. In particular, we shed light on two issues. First, we analyzed two different policies (fertilizer use and no fertilizer use) for overseeing the problem of soil fertility deterioration. Second, we identified a particular likelihood function and we showed that whether the problem of soil fertility impairment is best addressed with a fertilizer use policy or with a no fertilizer use policy depends essentially on this likelihood function. 
The analysis contained in this paper can be extended in a number of ways. In what follows, we propose two potential extensions of this paper's research. First, the reader will note that we modeled the stochastic decline in soil fertility on the CPFL with a Wiener process. Therefore, it would be interesting to examine the extent to which the results of this paper hold when alternate stochastic processes are used to model the random movement toward the fallow state. Second, it would be useful to compare the approach of this paper with an alternate approach in which in addition to the fallowing costs and the costs of fertilizer use, it is costly for a swidden cultivator to determine the current state of the stochastic process denoting soil fertility. Studies of fertilizer use in swidden agriculture that incorporate these aspects of the problem into the analysis will provide additional insights into how one might manage the problem of soil fertility deterioration. 


\section{References}

Antelman, G., and Savage, I.R. 1965. Surveillance Problems: Wiener Processes, Naval Research Logistics Quarterly, 12, 35-55.

Batabyal, A.A., and Yoo, S.J. 1994. Renewal Theory and Natural Resource Regulatory Policy Under Uncertainty, Economics Letters, 46, 237-241.

Batabyal, A.A., and Lee, D.M. 2003. Aspects of Land Use in Slash and Burn Agriculture, Applied Economics Letters, 10, 821-824.

Batabyal, A.A., and Beladi, H. 2004. Swidden Agriculture in Developing Countries, Review of Development Economics, 8, 255-265.

Brown, K., and Pearce, D.W., Eds. 1994. The Causes of Tropical Deforestation. University of British Columbia Press, Vancouver, British Columbia.

Coomes, O.T., Grimard, F., and Burt, G.J. 2000. Tropical Forests and Shifting Cultivation: Secondary Forest Fallow Dynamics Among Traditional Farmers of the Peruvian Amazon, Ecological Economics, 32, 109-124.

Dickinson, J.C. 1972. Alternatives to Monoculture in the Humid Tropics of Latin America, Professional Geographer, 24, 217-222.

Dove, M.R. 1983. Theories of Swidden Agriculture and the Political Economy of Ignorance, Agroforestry Systems, 1, 85-99.

Dufour, D.L. 1990. Use of Tropical Rainforests by Native Amazonians, BioScience, 40, 652-659.

Eckholm, E.P. 1976. Losing Ground. W.W. Norton, New York, New York.

Farnsworth, E.G., and Golley, F.B. Eds. 1973. Fragile Ecosystems. Springer-Verlag, New York, New York. 
Hofstad, O. 1997. Degradation Processes in Tanzanian Woodlands, Forum for Development Studies, $0,95-115$.

Li, F., Zhao, S., and Geballe, G.T. 2000. Water Use Patterns and Agronomic Performance for Some Cropping Systems With and Without Fallow Crops in a Semi-Arid Environment of Northwest China, Agriculture, Ecosystems, and Environment, 79, 129-142.

Pearce, D.W., and Warford, J.J. 1993. World Without End: Economics, Environment, and Sustainable Development. Oxford University Press, Oxford, UK.

Peters, W.J., and Neuenschwander, L.F. 1988. Slash and Burn: Farming in the Third World Forest. University of Idaho Press, Moscow, Idaho.

Ross, S.M. 1996. Stochastic Processes, $2^{\text {nd }}$ edition. Wiley, New York, New York.

Ross, S.M. 2003. Introduction to Probability Models, $8^{\text {th }}$ edition. Academic Press, San Diego, California.

Silva-Forsberg, M.C., and Fearnside, P.M. 1997. Brazilian Amazonian Caboclo Agriculture: Effect of Fallow Period on Maize Yield, Forest Ecology and Management, 97, 283-291.

Southgate, D. 1990. The Causes of Land Degradation along Spontaneously Expanding Agricultural Frontiers in the Third World, Land Economics, 66, 93-101.

Swinkels, R.A., Franzel, S., Shepherd, K.D., Ohlsson, E., and Ndufa, J.K. 1997. The Economics of Short Rotation Improved Fallows: Evidence From Areas of High Population Density in Western Kenya, Agricultural Systems, 55, 99-121.

Udaeyo, N.U., Umoh, G.S., and Ekpe, E.O. 2001. Farming Systems in Southeastern Nigeria: Implications for Sustainable Agricultural Production, Journal of Sustainable Agriculture, 17, 75-89. 
